Published in final edited form as:

ACS Chem Biol. 2016 April 15; 11(4): 1128-1136. doi:10.1021/acschembio.5b00993.

\title{
Isoxazole Alters Metabolites and Gene Expression, Decreasing Proliferation and Promoting a Neuroendocrine Phenotype in $\beta$ - Cells
}

\author{
Michael A. Kalwat ${ }^{\dagger}$, Zhimin Huang $^{\dagger, \perp}{ }^{,}$, Chonlarat Wichaidit ${ }^{\dagger}$, Kathleen McGlynn ${ }^{\dagger}$, Svetlana \\ Earnest ${ }^{\dagger}$, Claudia Savoia", Elhadji M. Dioum", Jay W. Schneider ${ }^{\ddagger}$, Michele R. Hutchison $\S, \#$, \\ and Melanie H. Cobb ${ }^{\dagger}{ }^{*}$
}

†Department of Phamacology, UT Southwestern Medical Center, Dallas, Texas 75235, United States $\neq$ Department of Internal Medicine, UT Southwestern Medical Center, Dallas, Texas 75235, United States ${ }^{\S}$ Department of Pediatrics, UT Southwestern Medical Center, Dallas, Texas 75235, United States "Nestle Institute of Health Sciences, Lausanne, Switzerland

\section{Abstract \\ Novel strategies are needed to modulate $\beta$-cell differentiation and function as potential $\beta$-cell replacement or restorative therapies for diabetes. We previously demonstrated that small molecules based on the isoxazole scaffold drive neuroendocrine phenotypes. The nature of the effects of isoxazole compounds on $\beta$-cells was incompletely defined. We find that isoxazole induces genes that support neuroendocrine and $\beta$-cell phenotypes and suppresses genes important for proliferation. Isoxazole alters $\beta$-cell metabolites and protects glucose-responsive signaling}

\footnotetext{
*Corresponding Author. melanie.cobb@utsouthwestern.edu.

- Present Addresses

UT Southwestern Visiting Scholar; permanent address: Department of Endocrinology and Diabetes Center, First Affiliated Hospital of Sun Yat-sen University, Guangzhou, Guangdong, China

\#Department of Pediatrics, Medical University of South Carolina, Charleston, SC 29425, USA

ASSOCIATED CONTENT

Supporting Information

The Supporting Information is available free of charge on the ACS Publications website at DOI: 10.1021/acschembio.5b00993.
}

Figure S1 legend, Tables S1-S3 legends, and Methods (PDF)

Figure S1 (PDF)

Human islet donor information, Table S1 (PDF)

Human islet donor information, Table S1 (XLSX)

Affymetrix HTA2.0 microarray for long-term cultured human islets treated for 7 days with ISX or DMSO, Table S2 (XLSX)

Unbiased metabolomic analysis of MIN6 cells treated for 2 days with ISX (10uM) or DMSO under high vs low glucose conditions, Table S3 (XLSX)

Author Contributions

Conceptualization, M.A.K., M.R.H., E.M.D., and M.H.C.; Software, C.W.; Formal Analysis, C.W. and M.A.K.; Investigation, M.A.K., Z.H., M.R.H. K.M., E.M.D., and S.E.; Writing-Original Draft, M.A.K. and M.H.C.; Supervision, M.R.H., J.W.S., and M.H.C.;

Funding Acquisition, M.H.C. and M.A.K.

The authors declare the following competing financial interest(s): E.M.D., J.W.S., and M.H.C. are inventors on United States Patent No. 9,221,800, entitled Isoxazole Treatments for Diabetes. 
pathways under lipotoxic conditions. Finally, we show that isoxazole improves glycemia in a mouse model of $\beta$-cell regeneration. Isoxazole is a prime candidate to alter cell fate in different contexts.

\section{Graphical abstract}

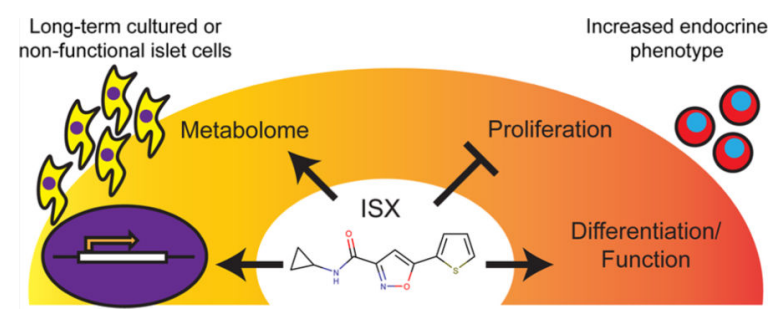

Type 1 diabetes (T1D) and type 2 diabetes (T2D) are devastating diseases that can cause a myriad of pathologies as a result of uncontrolled or poorly controlled hyperglycemia, including neuropathy, retinopathy, and nephropathy. ${ }^{1,2}$ Diabetes results when pancreatic islet $\beta$-cells fail to produce sufficient insulin to maintain euglycemia. ${ }^{1,3}$ In the case of T1D, insufficient insulin production is due to autoimmune destruction of $\beta$-cells, while in T2D $\beta$ cell failure occurs in the setting of insulin resistance due to multiple factors including genetic predisposition and environmental influences and is hastened by obesity and metabolic disorders. ${ }^{1}$ Therapeutic interventions to restore or improve $\beta$-cell function are widely sought and evaluated to treat $\mathrm{T} 1 \mathrm{D}$ and $\mathrm{T} 2 \mathrm{D} .^{2}$

The small molecule N-cyclopropyl-5-(thiophen-2-yl)-isoxazole-3-carboxamide (ISX) was discovered in a screen for activators of the transcription factor $\mathrm{Nkx} 2.5$ and was shown to improve cardiac function in a mouse cardiac repair assay ${ }^{4}$ and also promoted myofibroblast differentiation and wound healing in a mouse model. ${ }^{5}$ Characterization of the effects of ISX on neural stem cells revealed an ability to enhance neuronal gene expression in differentiation assays. ${ }^{6}$ ISX induced changes in the expression of many genes that were partially dependent on the phosphorylation of the histone deacetylase HDAC5 and its subsequent export from the nucleus. Recently, ISX was required to promote the conversion of fibroblasts to differentiated neurons. ${ }^{7}$ Further work has suggested that ISX selectively influences differentiation and proliferation depending on the particular stem/progenitor cell population. ${ }^{8}$ A modified ISX molecule forms hydrogels in vitro that bind many RNAs and RNA-binding proteins, ${ }^{9,10}$ suggesting ISX-like compounds may have the potential to elicit broad-sweeping changes in mRNA stability and gene expression.

Treatment with ISX increased insulin gene expression in human islet cells that had been maintained in long-term culture and resulted in partial restoration of glucose-stimulated insulin secretion. ${ }^{11}$ Global increases in histone 3 (H3) Lys9 and H3 Lys14 acetylation and histone 4 (H4) lysine acetylation were observed, apparently via the lysine acetyl transferase p300 and the related enzyme CREB binding protein, CBP. In contrast to findings in neural stem cells, no changes in HDAC activity were observed in $\beta$-cells exposed to ISX, ${ }^{11}$ suggesting multiple ISX-induced events may affect histone acetylation in different cell types. 
To elucidate the mechanisms of ISX action on $\beta$-cells, we have employed microarray analyses in long-term cultured human islets and metabolomic analyses in MIN6 $\beta$-cells. Defining these pharmacological actions in the $\beta$-cell is valuable for enhancing islet function under acute stress as well as in disease states. Experiments in the PANIC-ATTAC mouse model of $\beta$-cell death and regeneration suggest ISX is a stepping stone for future molecular designs aimed at diabetes therapies. Many small molecule screens have sought compounds which increase proliferation with the aim of increasing functional islet $\beta$-cell mass, but novel tools are necessary to balance this process by slowing proliferation and enhancing differentiation, and ISX fits this role.

\section{RESULTS AND DISCUSSION}

\section{ISX-induced Alterations in mRNAs in Long-term Cultured Human Islets}

ISX increases the accumulation of mRNAs encoding a select group of $\beta$-cell proteins essential for glucose sensing and insulin gene transcription including glucokinase, NeuroD1, MafA, and insulin itself in human islets that had been maintained in culture for several months to over a year. ${ }^{11}$ These changes partially restored insulin content and glucosestimulated insulin secretion (GSIS) in these long-term cultures. ${ }^{11}$

Human islet tissue samples are heterogeneous due to differences among donors (Table S1) and because the preparations contain many different cell types, including endocrine $\beta, a, \delta$, $\varepsilon$, and pancreatic polypeptide (PP) cells, and nonendocrine ductal, endothelial, and acinar cells. ${ }^{12}$ Our approach utilizes this mixed human islet cell culture to investigate the ability of cells in long-term culture to re-express islet factors. To examine global patterns of changes in mRNA content caused by ISX in islets, we collected RNA from human islet cells maintained in culture for 8-14 months that had been treated with ISX for 7 days preceding harvest. The samples were then subjected to transcriptome microarray analysis (HTA 2.0, Affymetrix). A total of 1179 transcripts were altered by greater than or equal to 2-fold in the ISX-treated cells compared to the DMSO-treated cells, 722 of which achieved significance in the array $(P<0.05$; Table S2). A scatter plot of the microarray expression data shows that up-regulation of transcripts outweighed down-regulation (Figure 1A), consistent with the suggested role of ISX as an inducer. ${ }^{7}$ Genes that were altered by more than 2 -fold and select genes that were previously published to be enriched in islets or beta cells (Table S2) were chosen for validation. qRT-PCR analysis confirmed that mRNAs encoding many isletenriched genes were induced by ISX (Figure 1B,C). A subset of ISX-induced genes have been found to be enriched in islet cells ${ }^{13}$ (Table S2). Among them, FAM105A expression was reported to be decreased in T2D human islets. ${ }^{14}$ Predicted to be an inactive deubiquitinase, nothing else about FAM105A in $\beta$-cells is known. UCP2, also increased in our microarray, has been linked to T2D in genome-wide association studies. ${ }^{15}$

Gene set enrichment analysis (GSEA) revealed sets of genes with relevance to $\beta$-cell function that were altered in our microarray and included genes necessary for insulin biosynthesis/secretion and genes affecting fatty acid metabolism (Figures S1C, 2A). For example, SLC27A2 is induced by ISX treatment of long-term cultured human islet-derived cells (Figure 1B). SLC27A2 is a long-chain fatty acyl-CoA synthase,,${ }^{16}$ and its protein level was increased by glucose in human islets. ${ }^{17}$ These findings establish the presence of 
SLC27A2 in islets; it was reported to be expressed primarily in the liver. ${ }^{18}$ SLC27A2 might play a role in the generation of acyl-CoA intermediates downstream of ISX.

Steroyl-CoA desaturase 5 (SCD5) was also increased (Figure 1B). A recent study of SCD5 demonstrated its role in neuronal differentiation. ${ }^{19} \mathrm{~A}$ portion of the altered genes has already been shown to be islet-enriched, $\beta$-cell-enriched, or implicated during $\beta$-cell development ${ }^{20-24}$ (Table S2). A subset of islet enriched genes was slightly increased (Figure 1C), to a lesser extent than the ones in Figure 1B. Variation inherent in different human donors and long-term culture likely impacts the extent of the response to ISX, since ISX treatment of particular batches of human islet cultures induced large responses in insulin expression as well as other islet genes. ${ }^{11}$

A cohort of the changed mRNAs was consistent with those detected in microarray analyses of other cell types treated with ISX. ${ }^{6}$ In particular, many of these genes are also increased by ISX in neuronal stem cells and are associated with neuronal function. For example, previous analyses of neural stem cells showed upregulation of Bex1, and we also observed this gene upregulated in human islets (Table S2).

Among genes whose expression was decreased, most were involved in proliferation and cell cycle progression including TOP2A, CDK1, PLK4, and CENP (Figure 1D). To test the hypothesis that ISX decreases cell proliferation, we measured cell viability and cell number in multiple assays in ISX-treated INS1E $\beta$-cells. ISX-treated INS1E proliferated more slowly using an assay that indirectly measures ATP (Figure 1E), but interestingly ISX had no effect in an assay that measures mitochondrial dehydrogenase activity (Figure 1F). Cell counting assays confirmed that ISX treatment indeed results in fewer cells (Figure 1G), suggesting ISX reduces proliferation but not viability.

Because our initial studies were focused on the capacity of ISX to improve the function of ex vivo aged islets, we asked if the same changes were apparent in islets obtained recently that retained high insulin content. We treated fresh human islets with ISX for 4 days to assess expression changes observed in our microarray of long-term cultured islets. Certain genes were altered in these fresh islets as they were in the microarray from aged islets, such as stathmin 2 (STMN2) and NTRK2 (Figure 1H), supporting specific effects of ISX on islet cell types. Alterations in cell cycle genes, insulin, and MafA expression were not highly significant, most likely because they were already expressed at appropriate amounts in fresh islets (Figure 1H). This is consistent with the notion that freshly isolated islets still contain sufficient insulin transcript and are still differentiated and functional compared to their longterm cultured counterparts.

\section{ISX Increases Gene Expression via Transcription and Not Stabilization}

Acetylation of H3 Lys9 and Lys14 and H4 are early readouts of ISX action detectable in the MIN6 $\beta$-cell line ${ }^{11}$ and observed in the 1.1B4 human $\beta$-cell line and rat INS1 $\beta$-cell lines (Figure S1A,B). STMN2 induction has also been an effective marker for ISX action. We found that not only was STMN2 mRNA upregulated by ISX in human islets, the protein was also induced in MIN6 cells (Figure 1I). To determine the rapidity of ISX action on mRNA accumulation, we measured a time course of STMN2 and insulin expression in MIN6 cells 
following exposure to ISX. Increased STMN2 expression was noted by $6 \mathrm{~h}$ after ISX addition and peaked at $18 \mathrm{~h}$ over the $24 \mathrm{~h}$ time course (Figure 1J). This onset was similar to induction of acetylated $\mathrm{H} 3 \mathrm{Lys} 9$ and phospho-ERK1/2 after exposure to ISX. ${ }^{11}$ We examined the effects of signaling inputs on the increase in STMN2 mRNA at $8 \mathrm{~h}$ and found that none of the agents tested fully prevented the increase in STMN2 expression (Figure S1D). However, significant decreases were observed by a blockade of voltage-gated calcium channels or calcium chelation (Figure S1D), fitting well with earlier studies examining the mechanisms of ISX action. ${ }^{6,11}$ Blocking protein synthesis and inhibiting the AMP-activated protein kinase AMPK with compound $\mathrm{C}$ caused roughly equivalent inhibition, while blocking ERK1/2 activation with a MEK inhibitor did not cause a statistically significant decrease (Figure S1D).

Because a biotinylated version of ISX was shown to form hydrogels in vitro and had the ability to precipitate many RNA-binding proteins from lysates, ${ }^{9,10}$ we tested the possibility that ISX stabilizes RNA in cells. To determine whether ISX exerts any of its effects via mRNA stabilization, as opposed to induction of transcription, we pretreated MIN6 cells with actinomycin D to block transcription in the presence of ISX. STMN2 mRNA generally has a long half-life, while MYC, DUSP1, and TOP2A have shorter half-lives. ${ }^{25}$ As expected, STMN2 was increased after $6 \mathrm{~h}$ with ISX (Figure 1K). TOP2A and DUSP1 were slightly decreased, and MYC was not affected by ISX (Figure 1K). Simultaneous exposure to actinomycin D resulted in significantly decreased accumulation of gene products with short half-lives in the control, while STMN2 transcripts were unaffected (Figure 1K). ISXstimulated increase in STMN2 was blocked in the presence of actinomycin D (Figure 1K), suggesting for the targets tested that ISX acts not through mRNA stabilization but through induction of transcription.

\section{ISX Prevents Loss of Glucose-induced ERK1/2 Activation Caused by Palmitate}

Because ISX-induced genes related to fatty acid metabolism were identified by GSEA analysis (e.g., ELOVL4, ELOVL2; Figure 2A) and our observations (e.g., SLC27A2, APOE, FABP3/5, SCD5), and because ISX also modulated histone modifications and ERK activation (Figure S1A,B), ${ }^{11}$ we tested whether ISX altered the $\beta$-cell response to lipotoxicity. A hallmark of lipotoxicity in $\beta$-cells is a reduced response to glucose stimulus. ${ }^{1,26}$ We observed a consistent loss in glucose-induced ERK activation when cells were exposed to chronic lipotoxicity (Figure 2B). This loss was mitigated by cotreatment with ISX (Figure 2B). These data suggest that ISX-mediated changes in gene expression lead to protection against palmitate toxicity, perhaps through alteration of gene expression or the metabolome.

\section{ISX Alters the Metabolome of MIN6 Cells}

Given the effects of ISX on the function of palmitate-treated $\beta$-cells, we performed metabolomic profiling of MIN6 cells treated with ISX for $48 \mathrm{~h}$ in high $(25 \mathrm{mM})$ or low (5 $\mathrm{mM}$ ) concentrations of glucose. Over 130 metabolites were confidently identified (Figure 3A), and principle component analysis showed consistent replicates (Figure 3B). Altering glucose concentration had the most profound impact on metabolite content (Figure 3C). High glucose increased malate and 5-aminoimidazole-4-carboxamide ribonucleotide 
(AICAR or ZMP) as shown in other metabolomic studies ${ }^{27,28}$ (Figures 3C and 4B,C). As expected, many glycolysis and TCA cycle intermediates were increased by high glucose (Figures 3B and 4C). Unexpectedly, certain acylcarnitines (C3, C5, C14, C16, and C18) were decreased by high glucose (Figures $1 \mathrm{~B}$ and $4 \mathrm{~A}$ ). Since our metabolomic analysis was done on cells growing under chronic high or low glucose conditions, we did not observe some of the acute metabolic changes seen in other $\beta$-cell and islet studies. ${ }^{27,28}$

ISX treatment decreased dodecanoylcarnitine (C12) in low glucose (Figure 4A). ISXinduced changes in acylcarnitines or protection against palmitate could be a result of increased SLC27A2 expression in combination with other genes involved in fatty acyl metabolism such as SCD5, ELOVL2, ELOVL4, and FABP3/5. Depending on the glucose concentration, ISX treatment changed a different cohort of metabolites, but metabolites induced or repressed by high glucose were generally unhindered by the presence of ISX (Figure 3C vs F). In low glucose, ISX elevated gluconic acid, which is able to be utilized in the cell largely through generation of gluconeogenic intermediates, ${ }^{29}$ and thus may facilitate increased energy utilization even under low glucose conditions. It is tempting to speculate that ISX generates oxidative conditions that drive glucose to gluconic acid to form intermediates which may contribute to protection from fatty acid stress.

Because ISX decreased proliferation, we analyzed nucleotide biosynthesis intermediates in our data set; generally, ISX had a minimal effect on these intermediates. Xanthosine-5monophosphate and GMP were decreased substantially only in low glucose (Figure 4D). ISX drastically lowered AICAR levels in either low or high glucose compared to the control (Figure 4B). While treatment of INS1 (832/13) cells with AICAR was shown to decrease ceramides and other metabolic pathways that might explain the involvement of AMPK in protection from fatty acids, exogenous AICAR was used at a concentration 150-fold higher than maximum endogenous levels, suggesting a minimal role for endogenous AICAR for its protective effects. ${ }^{28}$ Thus, the impact of chronic ISX treatment on endogenous AICAR levels is likely due to the role of AICAR in nucleotide biosynthesis. This hypothesis is supported by the lack of effect of ISX on AMPK phosphorylation (Figure S1E). Cells in high glucose had relatively higher abundance of nucleotide intermediates (Figure 4D). With the exception of 2-deoxycytidine in high glucose, these were mostly unaffected by ISX (Figure 4D).

\section{ISX Improved Oral Glucose Tolerance in PANIC-ATTAC Mice}

To determine the utility of ISX in vivo, we chose to study the PANIC-ATTAC mouse, as it is a robust model of $\beta$-cell recovery after ablation. The PANIC-ATTAC mouse expresses a caspase 8-FKBP fusion protein under control of the rat insulin promoter. Upon injection of a dimer-inducing compound, the fusion protein dimerizes and induces apoptosis specifically in $\beta$-cells. ${ }^{30}$ Philipp Scherer's group showed that either a PPAR $\gamma$ agonist or a GLP-1 analog aided in the recovery of PANIC-ATTAC mice from diabetes, establishing this model as a useful system for identifying treatments that impact $\beta$-cell recovery. ${ }^{31}$ Given the effects of ISX on long-term cultured human islets, we surmised that ISX may have pro- $\beta$-cell differentiation effects in vivo and may aid in the recovery of PANIC-ATTAC mice. Two injections of the dimerizer 1 day apart were administered to PANIC-ATTAC mice, and ISX 
injections began 1 week later. Injection of ISX daily for 4 weeks led to a significant reduction in blood glucose at $15 \mathrm{~min}$ after an oral glucose load (Figure 5A). Measurements showing reduced blood glucose, represented as area under the curve (AUC), during the oral glucose tolerance test (OGTT; Figure 5B) and increased total pancreas insulin content (Figure 5C) for ISX-treated mice approached significance. These results support the idea that ISX may have potential as an enhancer of $\beta$-cell function during stress and improve recovery during $\beta$-cell regeneration in PANIC-ATTAC mice. ISX is a compound with multifaceted utility.

ISX can drive fibroblast-to-neuron differentiation, ${ }^{7}$ enhance cardiac and neural differentiation in cell culture models and in vivo, ${ }^{4,6,32}$ and increase pancreatic islet $\beta$-cell gene expression. ${ }^{4,6,7,11,32}$ A plausible model is that ISX targets multiple pathways directly and indirectly, involving calcium-dependent signaling, histone acetylation, and the metabolic profile to cause decreased proliferation and increased differentiation in a cell contextdependent manner. Consistent with this interpretation, suppression of proliferation is thought to be required to allow human $\beta$-cells to fully differentiate in vitro, ${ }^{33}$ possibly involving the high energy consumption associated with the secretory pathway. ${ }^{34,35}$ Future studies on more potent ISX derivatives may assist in disentangling the multiple effects of ISX, elucidate novel regulatory pathways, and prove more efficacious in animal models.

\section{METHODS}

\section{Materials}

ISX (N-cyclopropyl-5-(thiophen-2-yl)isoxazole-3-carboxamide, CAS No. 832115-62-5) for mouse studies was a generous gift from Dr. Doug Frantz (UT San Antonio). ISX for other experiments was purchased from Chembridge. Rabbit anti-Stathmin2 (1:1000) was from Proteintech. Rabbit antibeta tubulin (sc-9104, 1:250) was from Santa Cruz. Mouse antiphosphorylated ERK1/2(Thr183/Tyr185) (\#9106, 1:1000), rabbit anti-AMPK (\#5832, 1:1000), and rabbit antiphospho-Thr172-AMPK (\#2535, 1:1000) were from Cell Signaling. Rabbit anti-ERK1/2 Y691 was made in-house. Mouse antihistone H3 (\#39763, 1:5000) was from ActiveMotif. Rabbit antiacetyl-H3 Lys9 (\#07-352, 1:5000) and rabbit antipan-acetyllysine H4 (\#06-866, 1:2000) were from Upstate. Sodium palmitate (P9767) was from Sigma, and fatty-acid free BSA (\#126579) was from Calbiochem. All other reagents were obtained through Fisher unless otherwise stated.

\section{Microarray Analysis}

RNA was collected from three independent sets of long-term cultured human islets treated for 7 days with $20 \mu \mathrm{M}$ ISX using the PureLink RNA Mini Kit (Life Technologies). RNA samples that passed bioanalyzer chip testing were used in microarrays with the GeneChip Human Transcriptome Array 2.0 (Affymetrix). Microarray data were normalized and analyzed using Expression Console and Transcriptome Analysis Console v2.0 software from Affymetrix. Array data are deposited in the NCBI GEO database (GEO: GSE74240). 


\section{Culture and Treatment of $\beta$-Cell Lines}

MIN6 $\beta$-cells were cultured in complete MIN6 medium (Dulbecco's modified Eagle's medium ( $25 \mathrm{mM}$ glucose), supplemented with $15 \%$ fetal bovine serum, 100 units $\mathrm{mL}^{-1}$ penicillin, $100 \mu \mathrm{g} \mathrm{mL}^{-1}$ streptomycin, $292 \mu \mathrm{g} \mathrm{mL}^{-1} \mathrm{~L}$-glutamine, and $50 \mu \mathrm{M} \beta$ mercaptoethanol) as described previously. ${ }^{37}$ For experiments in which cells were starved and stimulated, MIN6 cells were washed twice with and incubated for $2 \mathrm{~h}$ in freshly prepared modified Krebs-Ringer bicarbonate buffer (MKRBB: $5 \mathrm{mM} \mathrm{KCl}, 120 \mathrm{mM} \mathrm{NaCl}, 15 \mathrm{mM}$ HEPES, pH 7.4, $24 \mathrm{mM} \mathrm{NaHCO}_{3}, 1 \mathrm{mM} \mathrm{MgCl}_{2}, 2 \mathrm{mM} \mathrm{CaCl} 2$, and $1 \mathrm{mg} \mathrm{mL}^{-1}$ radioimmunoassay-grade $\mathrm{BSA}$ ). Cells were stimulated with $20 \mathrm{mM}$ glucose as indicated. Cells were lysed in either radioimmunoprecipitation assay (RIPA) buffer for histone acetylation experiments or 1\% Nonidet P-40 (NP-40) lysis buffer (25 mM HEPES, pH 7.4, $1 \%$ Nonidet P-40, $10 \%$ glycerol, $50 \mathrm{mM}$ sodium fluoride, $10 \mathrm{mM}$ sodium pyrophosphate, $137 \mathrm{mM} \mathrm{NaCl}, 1 \mathrm{mM}$ sodium vanadate, $1 \mathrm{mM}$ phenylmethylsulfonyl fluoride, $10 \mu \mathrm{g} \mathrm{mL}-1$ aprotinin, $1 \mu \mathrm{g} \mathrm{mL}-1$ pepstatin, $5 \mu \mathrm{g} \mathrm{mL}^{-1}$ leupeptin) for all other experiments and cleared of insoluble material by centrifugation at $10,000 \mathrm{~g}$ for $10 \mathrm{~min}$ at $4{ }^{\circ} \mathrm{C}$ for subsequent immunoblotting. INS1E cells were cultured in RPMI-1640 containing $10 \%$ fetal bovine serum, $100 \mathrm{U} \mathrm{mL}^{-1}$ penicillin and $100 \mu \mathrm{gL}^{-1}$ streptomycin. INS1E cells $\left(2 \times 10^{5}\right.$ cells $)$ were plated in 96-well plates and treated with vehicle or increasing concentrations of ISX for $72 \mathrm{~h}$. Cell proliferation was assayed with the Vialight kit (Lonza) which measures ATP. Cell viability was assayed with the Sensolyte kit (Anaspec) which measures lactate dehydrogenase activity. Cell number was also determined following trypsinization.

\section{Human Islet Culture and Treatments}

Human islets were obtained through the Integrated Islet Distribution Program (IIDP) and from the University of Alabama Islet Resource Facility. Donor information is provided in Table S1. Upon receipt, human islets were cultured in RPMI-1640 containing 10\% fetal bovine serum, $100 \mathrm{U} \mathrm{mL}^{-1}$ penicillin, and $100 \mu \mathrm{g} \mathrm{mL}-1$ streptomycin. For short-term culture, islets were treated the day after receipt. For long-term culture, islets were transferred to T75 flasks and allowed to attach. The medium was changed twice weekly, and islets were trypsinized and subcultured as described previously. ${ }^{11}$

\section{Quantitative PCR (qPCR)}

RNA was isolated from MIN6 cells using TRI-reagent (Fisher) and from human islets using the PureLink RNA Mini Kit (Life Technologies). Next, $0.5 \mu \mathrm{g}$ and $1 \mu \mathrm{g}$ of islet and MIN6 RNA, respectively, were converted into cDNA using the iScript kit (Bio-Rad), and the resulting cDNA was diluted 10-fold or 20-fold with water, respectively. A total of $2 \mu \mathrm{L}$ of diluted cDNA was used in $20 \mu \mathrm{L}$ qPCR reactions using $2 \times$ SYBR Bio-Rad master mix and $250 \mathrm{nM}$ of each primer. qPCR data were analyzed using the Bio-Rad CFX Manager software. Primers used are listed in the Supporting Information Experimental Procedures.

\section{Palmitate Treatment of $\beta$-cells}

A palmitate stock solution of $150 \mathrm{mM}$ in $50 \%$ ethanol was made by heating at $65{ }^{\circ} \mathrm{C}$ for 15 min with stirring. Stocks were aliquoted and stored at $-20{ }^{\circ} \mathrm{C}$. A total of $10 \mathrm{~mL}$ of $10 \%$ fatty acid-free BSA in water was warmed to $37^{\circ} \mathrm{C}$, and $333 \mu \mathrm{L}$ of $150 \mathrm{mM}$ palmitate or $50 \%$ 
ethanol was added and incubated for $1 \mathrm{~h}$ at $37^{\circ} \mathrm{C}$ with rotation. The $10 \mathrm{~mL}$ was then added to $90 \mathrm{~mL}$ of serum-free MIN6 medium. MIN6 cells were grown to $~ 70 \%$ confluence, and the media were exchanged for BSA- or palmitate-containing media with $0.1 \%$ DMSO or 20 $\mu \mathrm{M}$ ISX. After $48 \mathrm{~h}$, cells were starved and stimulated as described.

\section{Metabolomic Analysis}

Metabolomic studies were performed as previously described. ${ }^{36}$ See the Supporting Information.

\section{Mouse Studies}

Animals were housed and all experiments were conducted under humidity- and temperaturecontrolled conditions $\left(22-25+1{ }^{\circ} \mathrm{C}\right)$, on a $12 \mathrm{~h} \mathrm{light/dark} \mathrm{cycle} \mathrm{at} \mathrm{the} \mathrm{Animal} \mathrm{Resources}$ Center at UT Southwestern Medical Center (IACUC protocol number 2011-0201). Mice were fed standard chow (Harlan Teklad Global 2016) ad libitum and at all times had free access to water. ISX was dissolved in $20 \%$ hydroxypropyl- $\beta$-cyclodextrin (HPCD; AC29756-5000; Fisher Scientific) at $2 \mathrm{mg} \mathrm{mL}^{-1}$ final concentration. PANIC-ATTAC mice have been described. ${ }^{31}$ Briefly, male mice at $8-12$ weeks of age were injected with dimerizer once per day for 2 days. After 1 week, fasting blood glucose was measured to confirm a diabetic phenotype, and ISX injections were begun. Mice were injected intraperitoneally once daily with $16 \mathrm{mg} / \mathrm{kg}$ ISX or equivalent amount of HPCD vehicle. After 28 days, mice were subjected to an oral glucose tolerance test (OGTT). Mice were fasted for $6 \mathrm{~h}$ and then received $1 \mathrm{~g} / \mathrm{kg}$ glucose by gavage, and blood glucose levels were measured at $0,15,30,60$, 90, and $120 \mathrm{~min}$. After overnight recovery, mice were sacrificed, pancreata harvested, and insulin extracted by acid-ethanol. Total pancreas insulin content was measured by Mouse Insulin ELISA (Mercodia) and normalized to total protein using the Bradford assay.

\section{Statistical Analysis}

All quantitated data are expressed as mean \pm SE. Data were evaluated using Student's $t$ test and considered significant if $P<0.05$. Graphs were made in GraphPad Prism 6.

\section{Supplementary Material}

Refer to Web version on PubMed Central for supplementary material.

\section{Acknowledgments}

The microarray was performed at the UT Southwestern Microarray core facility. Thanks to R. DeBerardinis, Z. Hu, and C. Klimko at the Children's Medical Center Research Institute for assistance with metabolomic studies. We thank D. Waite for assistance with mouse work, S. Goetsch and J. Russell for experimental advice, and D. Ware for administrative assistance. We thank D. Frantz for graciously providing the ISX used in mouse studies. We are grateful to P. Scherer for sharing the PANIC-ATTAC mice. This work was funded by National Instititues of Health R01 DK55310 (to M.H.C.) and NRSA DK100113 (to M.A.K.). Z.H. was funded through the Exchange Scholars from Sun Yat-sen University (SYSU) in China. M.R.H. was funded by R03 DK089151. J.W.S. was funded through U01 484 HL100401 and CPRIT RP110486-P5. We acknowledge funding from Lone Star Heart, Inc. for early parts of this work. 


\section{REFERENCES}

1. Prentki M, Nolan CJ. Islet beta cell failure in type 2 diabetes. J. Clin. Invest. 2006; 116:1802-1812. [PubMed: 16823478]

2. Vetere A, Choudhary A, Burns SM, Wagner BK. Targeting the pancreatic beta-cell to treat diabetes. Nat. Rev. Drug Discovery. 2014; 13:278-289. [PubMed: 24525781]

3. Ashcroft FM, Rorsman P. Diabetes mellitus and the beta cell: the last ten years. Cell. 2012; 148:1160-1171. [PubMed: 22424227]

4. Sadek H, Hannack B, Choe E, Wang J, Latif S, Garry MG, Garry DJ, Longgood J, Frantz DE, Olson EN, Hsieh J, Schneider JW. Cardiogenic small molecules that enhance myocardial repair by stem cells. Proc. Natl. Acad. Sci. U. S. A. 2008; 105:6063-6068. [PubMed: 18420817]

5. Velasquez LS, Sutherland LB, Liu Z, Grinnell F, Kamm KE, Schneider JW, Olson EN, Small EM. Activation of MRTF-A-dependent gene expression with a small molecule promotes myofibroblast differentiation and wound healing. Proc. Natl. Acad. Sci. U. S. A. 2013; 110:16850-16855. [PubMed: 24082095]

6. Schneider JW, Gao Z, Li S, Farooqi M, Tang TS, Bezprozvanny I, Frantz DE, Hsieh J. Smallmolecule activation of neuronal cell fate. Nat. Chem. Biol. 2008; 4:408-410. [PubMed: 18552832]

7. Li X, Zuo X, Jing J, Ma Y, Wang J, Liu D, Zhu J, Du X, Xiong L, Du Y, Xu J, Xiao X, Wang J, Chai Z, Zhao Y, Deng H. Small-molecule-driven direct reprogramming of mouse fibroblasts into functional neurons. Cell Stem Cell. 2015; 17:195-203. [PubMed: 26253201]

8. Koh SH, Liang AC, Takahashi Y, Maki T, Shindo A, Osumi N, Zhao J, Lin H, Holder JC, Chuang TT, McNeish JD, Arai K, Lo EH. Differential effects of isoxazole-9 on neural stem/progenitor cells, oligodendrocyte precursor cells, and endothelial progenitor cells. PLoS One. 2015; 10:e138724. [PubMed: 26407349]

9. Kato M, Han TW, Xie S, Shi K, Du X, Wu LC, Mirzaei H, Goldsmith EJ, Longgood J, Pei J, Grishin NV, Frantz DE, Schneider JW, Chen S, Li L, Sawaya MR, Eisenberg D, Tycko R, McKnight SL. Cell-free formation of RNA granules: low complexity sequence domains form dynamic fibers within hydrogels. Cell. 2012; 149:753-767. [PubMed: 22579281]

10. Han TW, Kato M, Xie S, Wu LC, Mirzaei H, Pei J, Chen M, Xie Y, Allen J, Xiao G, McKnight SL. Cell-free formation of RNA granules: bound RNAs identify features and components of cellular assemblies. Cell. 2012; 149:768-779. [PubMed: 22579282]

11. Dioum EM, Osborne JK, Goetsch S, Russell J, Schneider JW, Cobb MH. A small molecule differentiation inducer increases insulin production by pancreatic beta cells. Proc. Natl. Acad. Sci. U. S. A. 2011; 108:20713-20718. [PubMed: 22143803]

12. Halban PA, Powers SL, George KL, Bonner-Weir S. Spontaneous reassociation of dispersed adult rat pancreatic islet cells into aggregates with three-dimensional architecture typical of native islets. Diabetes. 1987; 36:783-790. [PubMed: 3556277]

13. Nica AC, Ongen H, Irminger JC, Bosco D, Berney T, Antonarakis SE, Halban PA, Dermitzakis ET. Cell-type, allelic, and genetic signatures in the human pancreatic beta cell transcriptome. Genome Res. 2013; 23:1554-1562. [PubMed: 23716500]

14. Taneera J, Lang S, Sharma A, Fadista J, Zhou Y, Ahlqvist E, Jonsson A, Lyssenko V, Vikman P, Hansson O, Parikh H, Korsgren O, Soni A, Krus U, Zhang E, Jing XJ, Esguerra JL, Wollheim CB, Salehi A, Rosengren A, Renstrom E, Groop L. A systems genetics approach identifies genes and pathways for type 2 diabetes in human islets. Cell Metab. 2012; 16:122-134. [PubMed: 22768844]

15. Lee HJ, Ryu HJ, Shin HD, Park BL, Kim JY, Cho YM, Park KS, Song J, Oh B. Associations between polymorphisms in the mitochondrial uncoupling proteins (UCPs) with T2DM. Clin. Chim. Acta. 2008; 398:27-33. [PubMed: 18755175]

16. Watkins PA, Ellis JM. Peroxisomal acyl-CoA synthetases. Biochim. Biophys. Acta, Mol. Basis Dis. 2012; 1822:1411-1420.

17. Schrimpe-Rutledge AC, Fontes G, Gritsenko MA, Norbeck AD, Anderson DJ, Waters KM, Adkins JN, Smith RD, Poitout V, Metz TO. Discovery of novel glucose-regulated proteins in isolated human pancreatic islets using LC-MS/MS-based proteomics. J. Proteome. Res. 2012; 11:35203532. [PubMed: 22578083] 
18. Ge F, Zhou S, Hu C, Lobdell H, Berk PD. Insulin- and leptin-regulated fatty acid uptake plays a key causal role in hepatic steatosis in mice with intact leptin signaling but not in ob/ob or db/db mice. Am. J. Physiol Gastrointest. Liver Physiol. 2010; 299:G855-G866. [PubMed: 20595619]

19. Sinner DI, Kim GJ, Henderson GC, Igal RA. StearoylCoA desaturase-5: a novel regulator of neuronal cell proliferation and differentiation. PLoS One. 2012; 7:e39787. [PubMed: 22745828]

20. Blum B, Hrvatin SS, Schuetz C, Bonal C, Rezania A, Melton DA. Functional beta-cell maturation is marked by an increased glucose threshold and by expression of urocortin 3. Nat. Biotechnol. 2012; 30:261-264. [PubMed: 22371083]

21. Sabatini PV, Krentz NA, Zarrouki B, Westwell-Roper CY, Nian C, Uy RA, Shapiro AM, Poitout V, Lynn FC. Npas4 is a novel activity-regulated cytoprotective factor in pancreatic beta-cells. Diabetes. 2013; 62:2808-2820. [PubMed: 23656887]

22. Martens GA, Jiang L, Hellemans KH, Stange G, Heimberg H, Nielsen FC, Sand O, Van Helden J, Gorus FK, Pipeleers DG. Clusters of conserved beta cell marker genes for assessment of beta cell phenotype. PLoS One. 2011; 6:e24134. [PubMed: 21912665]

23. Kluth O, Matzke D, Kamitz A, Jahnert M, Vogel H, Scherneck S, Schulze M, Staiger H, Machicao F, Haring HU, Joost HG, Schurmann A. Identification of four mouse diabetes candidate genes altering beta-cell proliferation. PLoS Genet. 2015; 11:e1005506. [PubMed: 26348837]

24. Kluth O, Matzke D, Schulze G, Schwenk RW, Joost HG, Schurmann A. Differential transcriptome analysis of diabetes-resistant and -sensitive mouse islets reveals significant overlap with human diabetes susceptibility genes. Diabetes. 2014; 63:4230-4238. [PubMed: 25053586]

25. Sharova LV, Sharov AA, Nedorezov T, Piao Y, Shaik N, Ko MS. Database for mRNA half-life of 19977 genes obtained by DNA microarray analysis of pluripotent and differentiating mouse embryonic stem cells. DNA Res. 2009; 16:45-58. [PubMed: 19001483]

26. Poitout V, Robertson RP. Glucolipotoxicity: Fuel Excess and \{beta\}-Cell Dysfunction. Endocr. Rev. 2007; 29:351. [PubMed: 18048763]

27. Spegel P, Sharoyko VV, Goehring I, Danielsson AP, Malmgren S, Nagorny CL, Andersson LE, Koeck T, Sharp GW, Straub SG, Wollheim CB, Mulder H. Time-resolved metabolomics analysis of beta-cells implicates the pentose phosphate pathway in the control of insulin release. Biochem. J. 2013; 450:595-605. [PubMed: 23282133]

28. ElAzzouny MA, Evans CR, Burant CF, Kennedy RT. Metabolomics analysis reveals that AICAR affects glycerolipid, ceramide and nucleotide synthesis pathways in INS-1 cells. PLoS One. 2015; 10:e0129029. [PubMed: 26107620]

29. Stetten MR, Topper YJ. Pathways from gluconic acid to glucose in vivo. J. Biol. Chem. 1953; 203:653-664. [PubMed: 13084635]

30. Zheng F, Luo Y, Wang H. Regulation of brain-derived neurotrophic factor-mediated transcription of the immediate early gene Arc by intracellular calcium and calmodulin. J. Neurosci. Res. 2009; 87:380-392. [PubMed: 18798281]

31. Wang ZV, Mu J, Schraw TD, Gautron L, Elmquist JK, Zhang BB, Brownlee M, Scherer PE. PANIC-ATTAC: a mouse model for inducible and reversible beta-cell ablation. Diabetes. 2008; 57:2137-2148. [PubMed: 18469203]

32. Russell JL, Goetsch SC, Aguilar HR, Frantz DE, Schneider JW. Targeting native adult heart progenitors with cardiogenic small molecules. ACS Chem. Biol. 2012; 7:1067-1076. [PubMed: 22413910]

33. Scharfmann R, Pechberty S, Hazhouz Y, von Bulow M, Bricout-Neveu E, Grenier-Godard M, Guez F, Rachdi L, Lohmann M, Czernichow P, Ravassard P. Development of a conditionally immortalized human pancreatic beta cell line. J. Clin. Invest. 2014; 124:2087-2098. [PubMed: 24667639]

34. Webb GC, Akbar MS, Zhao C, Steiner DF. Expression profiling of pancreatic beta cells: glucose regulation of secretory and metabolic pathway genes. Proc. Natl. Acad. Sci. U. S. A. 2000; 97:5773-5778. [PubMed: 10811900]

35. Schuit F, Flamez D, De Vos A, Pipeleers D. Glucose-regulated gene expression maintaining the glucose-responsive state of beta-cells. Diabetes. 2002; 51(Suppl 3):S326-S332. [PubMed: 12475771] 
36. Mullen AR, Hu Z, Shi X, Jiang L, Boroughs LK, Kovacs Z, Boriack R, Rakheja D, Sullivan LB, Linehan WM, Chandel NS, DeBerardinis RJ. Oxidation of alpha-ketoglutarate is required for reductive carboxylation in cancer cells with mitochondrial defects. Cell Rep. 2014; 7:1679-1690. [PubMed: 24857658]

37. Kalwat MA, Wiseman DA, Luo W, Wang Z, Thurmond DC. Gelsolin associates with the N terminus of syntaxin 4 to regulate insulin granule exocytosis. Mol. Endocrinol. 2012; 26:128-141. [PubMed: 22108804] 
A

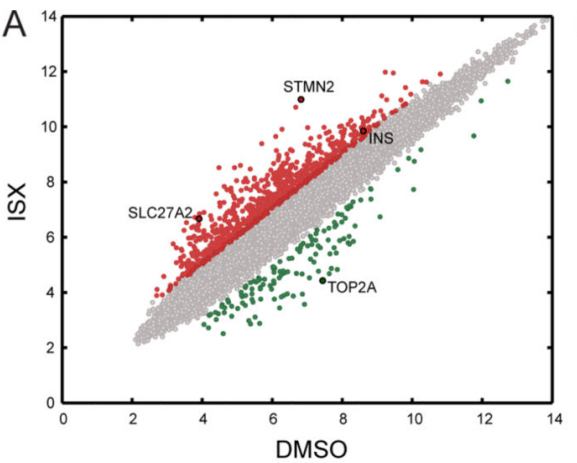

C

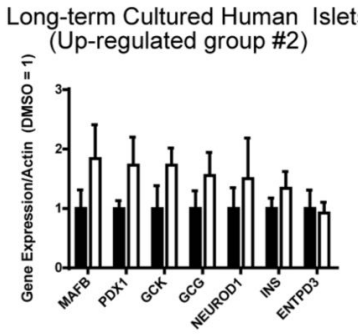

$\mathrm{E}$

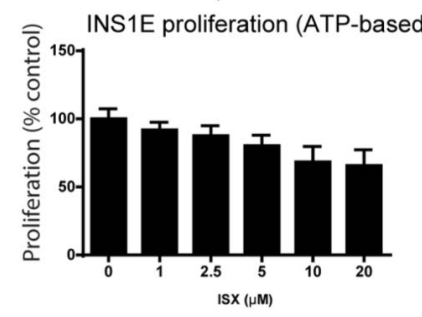

B

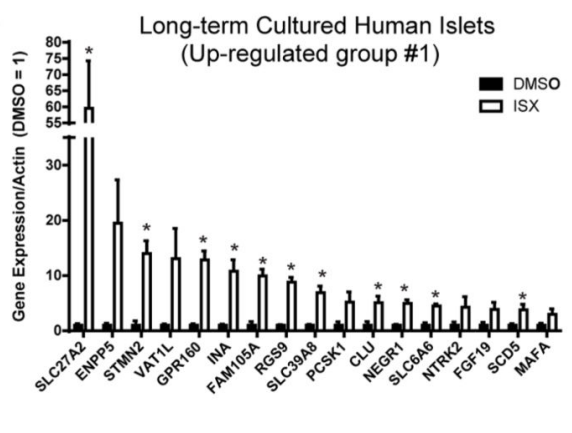

D

Long-term Cultured Human Islets

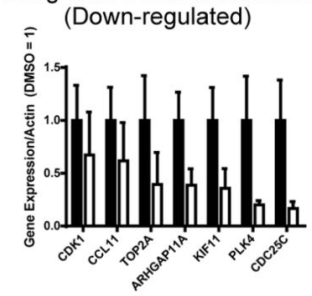

$\mathrm{F}$

INS1E proliferation (LDH-based)

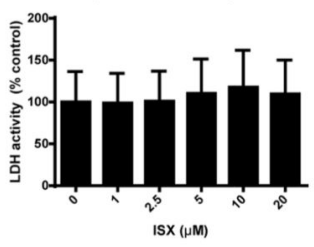

G INS1E proliferation (cell number) $\mathrm{H}$

Short-term Cultured Human Islets
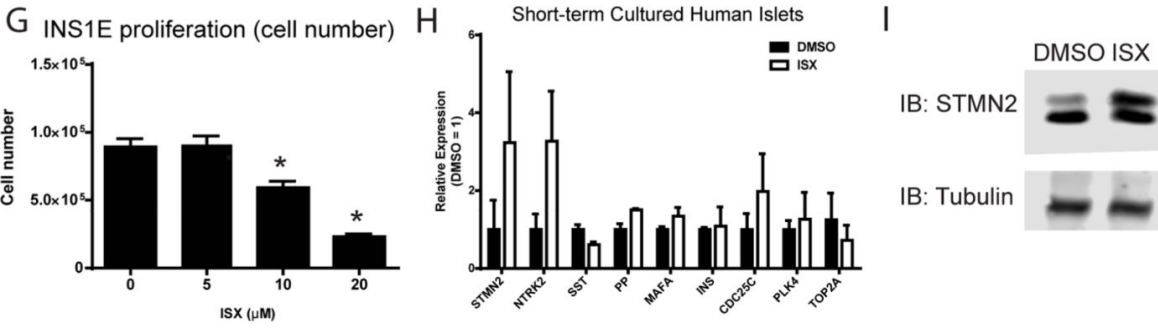

IB: STMN2

IB: Tubulin
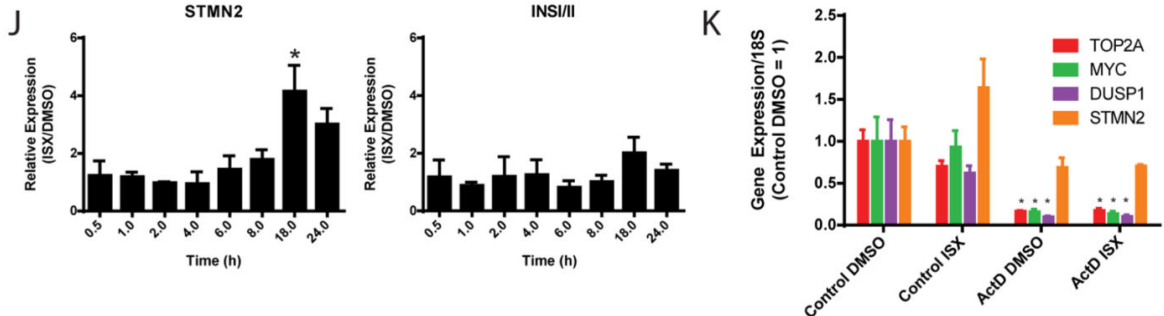

Figure 1.

Neuroendocrine gene expression phenotype induced by ISX in cultured human islets and mouse MIN6 $\beta$ cells. (A) Microarray analysis of long-term cultured human islets treated with DMSO or ISX for 7 days. See Table S1 for human islet donor information. (B-D) qPCR confirmation of selected ISX target genes from long-term cultured human islets. Relative expression is shown for genes that were highly up-regulated (B), moderately upregulated (C), or down-regulated (D). *, $P<0.05$. (E) ISX dose-response in INS1E cells shows that ISX slightly decreases proliferation measured indirectly by relative amount of 
ATP. (F) ISX dose-response in INS1E cells shows no change in viability by lactate dehydrogenase (LDH) activity. (G) ISX dose-dependently lowers cell number in a standard cell counting assay after $72 \mathrm{~h}$. (H) Validation of gene expression altered by ISX in short-term cultured human islets. (I) MIN6 cells were treated with ISX $(20 \mu \mathrm{M})$ for 2 days, and protein levels of STMN2 were monitored by immunoblotting. *, STMN2 protein increased. (J) MIN6 cells were treated with ISX $(20 \mu \mathrm{M})$ or DMSO for the indicated times, and gene expression of STMN2 and INSI/II relative to actin were monitored by qPCR. Data are expressed as the ratio of ISX/DMSO for each time point. *, $P<0.05$. (K) MIN6 cells were cotreated with ISX $(20 \mu \mathrm{M})$ and actinomycin $\mathrm{D}(5 \mu \mathrm{g} / \mathrm{mL})$ for $6 \mathrm{~h}$, and indicated gene expression was monitored by qPCR. All bar graphs are the average and SE of at least three independent experiments. ${ }^{*}, P<0.05$. 

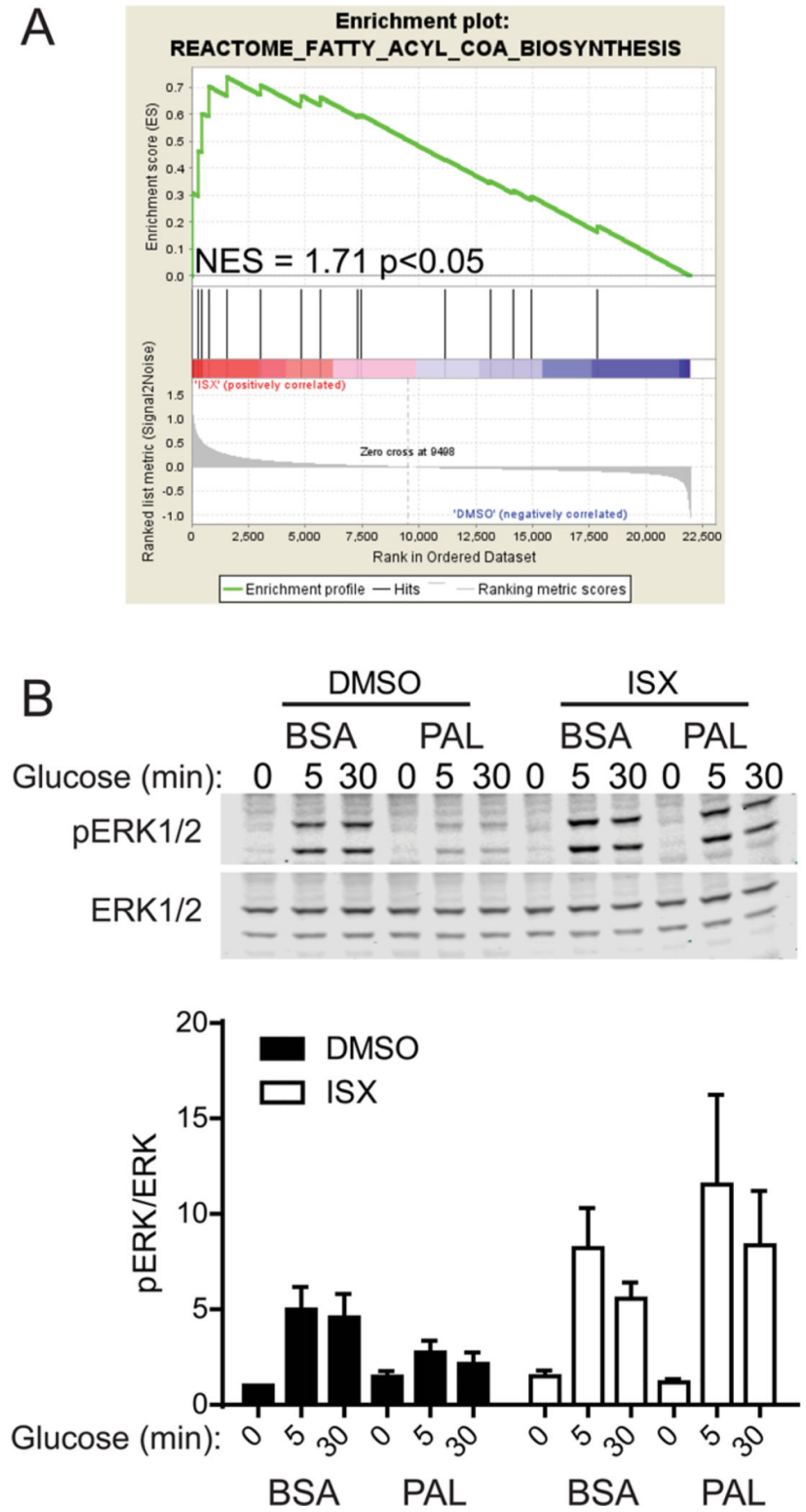

Figure 2.

MIN6 cell phospho-ERK1/2 response to glucose in the presence of palmitate preserved by ISX. (A) Gene set enrichment analysis indicating a significant normalized enrichment score (NES) for ISX-induced genes in the fatty acyl-CoA biosynthesis pathway. (B)

Representative immunoblots for phospho- and total ERK1/2. Below shows a bar graph of the average and SE of three independent experiments. Phospho/total-ERK1/2 ratio was normalized to basal BSA DMSO control. 
A

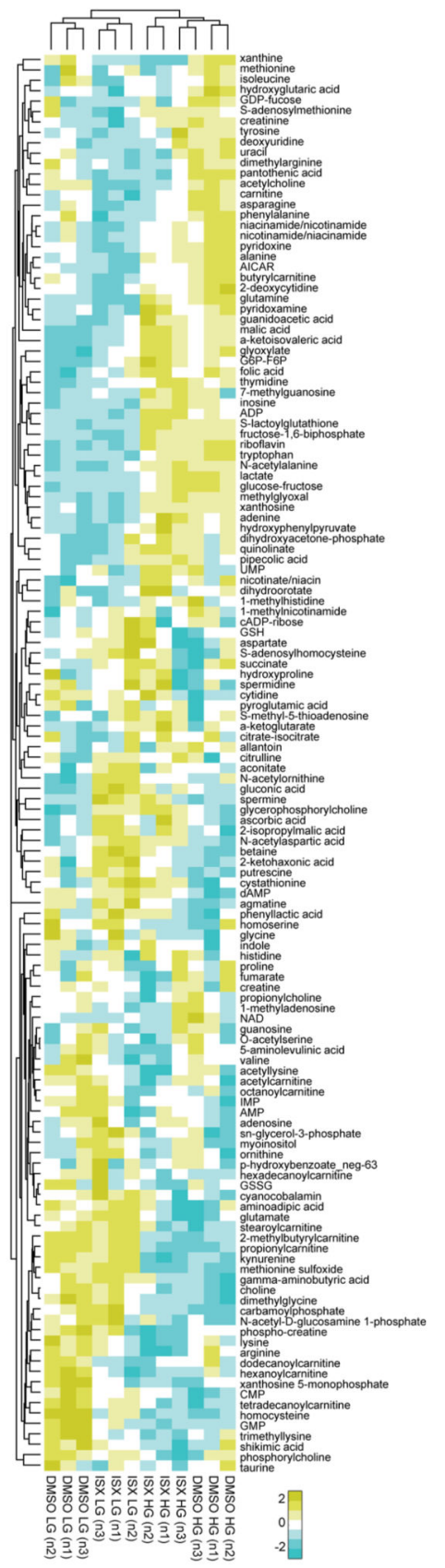

B

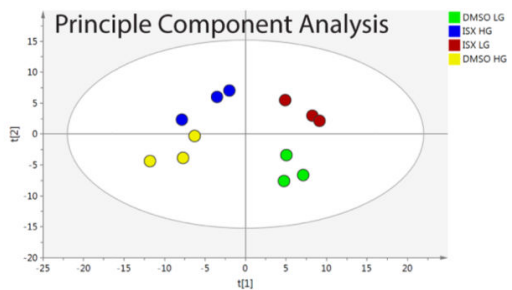

C

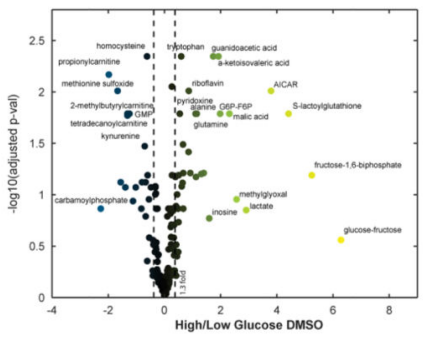

D

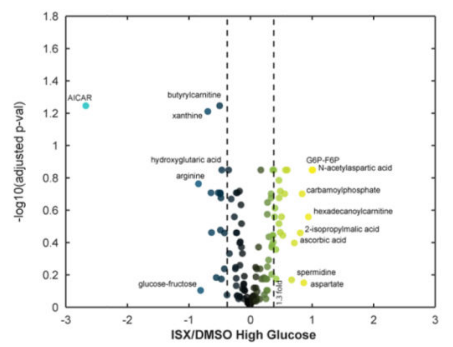

$\mathrm{E}$

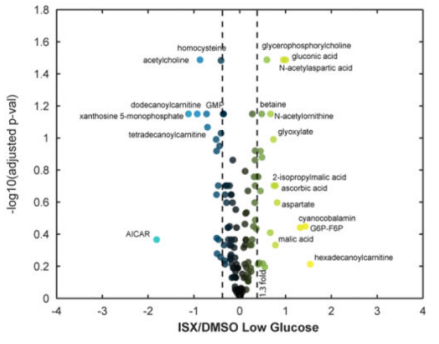

$\mathrm{F}$

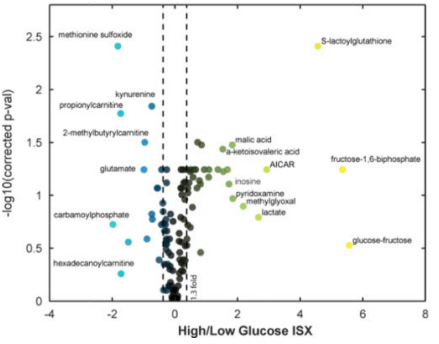

Figure 3.

Metabolomic response to chronic high or low glucose altered by ISX. (A) Relative abundances of metabolites extracted from three independent passages of MIN6 cells. Coloring reflects a $\log 2$ scale. (B-E) Volcano plots display the $\log 10$ (adjusted $\mathrm{p}$ value) on the $y$ axis and the fold-change in relative abundance on thexaxis for all metabolites detected in the shown comparisons. Coloring labels fold-change, with blue being down-regulated and yellow being up-regulated. 


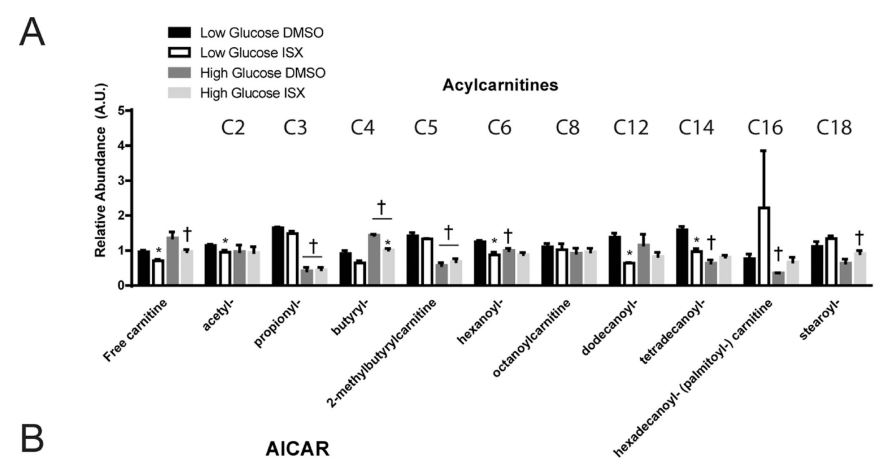

B

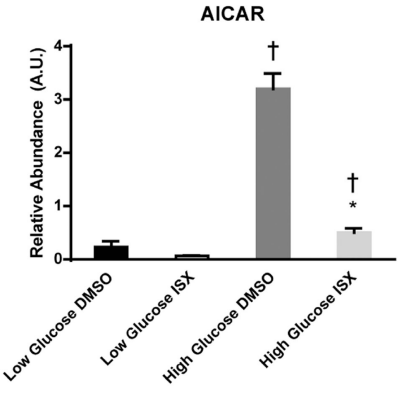

C

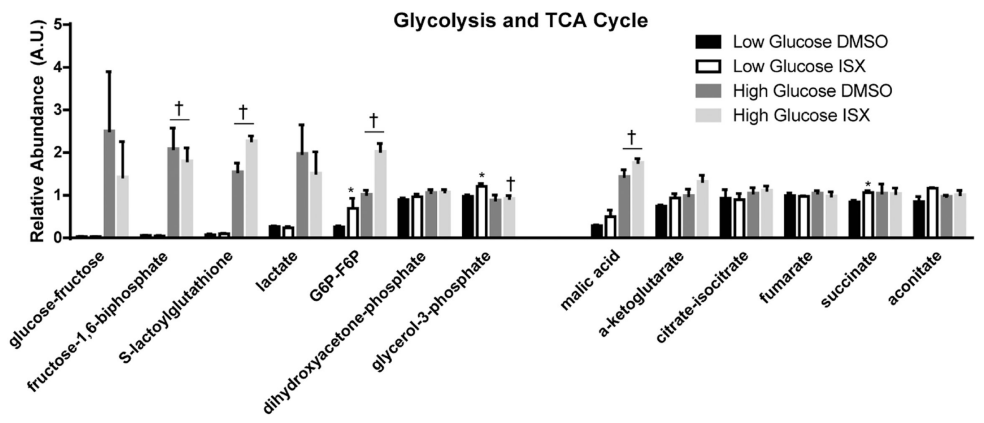

D

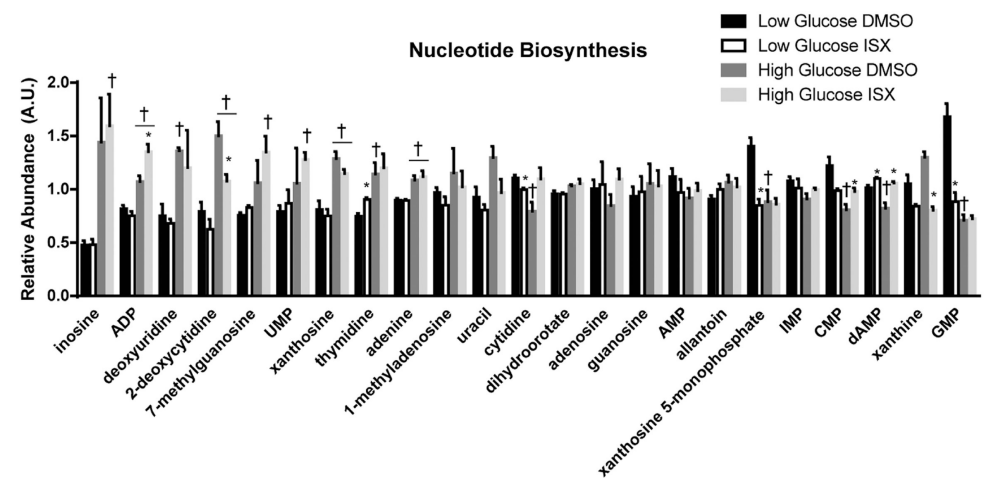

Figure 4.

Metabolites altered by ISX in multiple pathways. Relative amounts of metabolites from LCMS/MS analyses are shown. (A) Glycolysis and tricarboxylic acid cycle intermediate levels. (B) Metabolites involved in nucleotide biosynthesis are shown. (C) Detected acylcarnitines are shown in order of increasing carbon chain length. (D) Levels of 5-aminoimidazole-4carboxamide ribonucleotide (AICAR) are shown. (E) Principle component analysis of metabolomic data shows that replicate samples cluster together. All bar graphs are the 
average and SE of three independent experiments. * $P<0.05$ DMSO vs ISX, H, $P<0.05$ high vs low glucose. 
A

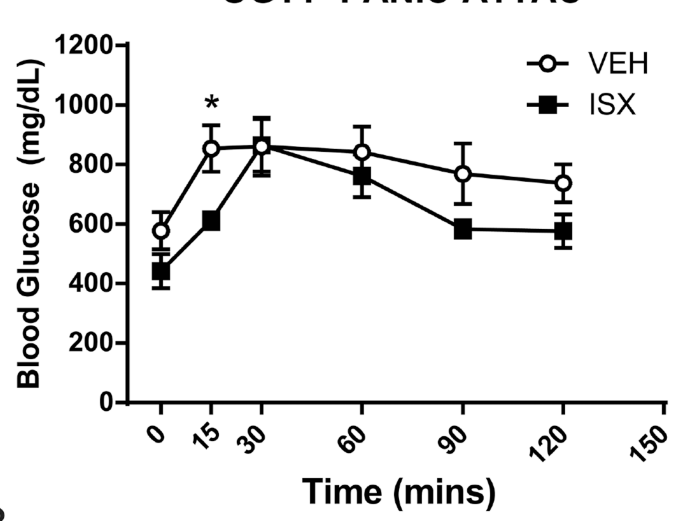

B
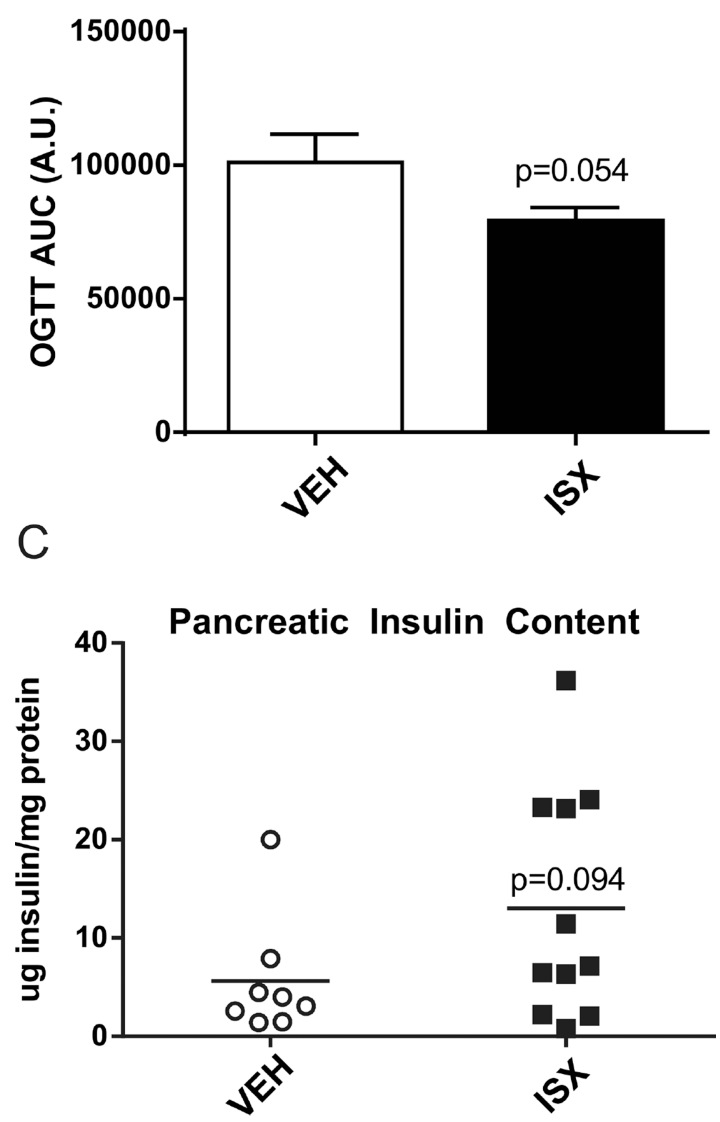

Figure 5.

Hyperglycemia in PANIC-ATTAC mice abrogated by ISX treatment during OGTT and whole pancreas insulin content increased. (A) Oral glucose tolerance test (OGTT) in control ISX-treated PANIC-ATTAC mice. (B) Area-under-the-curve (AUC) calculation of the OGTT data from A. A.U., arbitrary units. (C) Pancreata from A were acid-ethanol extracted, and insulin was measured with an ELISA. Data are the average and SE of 6-8 vehicle- and 10-11 ISX-treated mice. $* P<0.05$. 